\title{
The Use of Bristol's tool in lactation Counseling and its Impact on the Breastfeeding Status in Primiparous Mothers Undergone Cesarean Section
}

\author{
Parisa Parsa ${ }^{1}$, Raheleh Khodabandelou ${ }^{2}$, Farzaneh Soltani ${ }^{*}$, Younes Mohammadi ${ }^{4}$ \\ 1. Associate Professor, Ph.D. in Health Society, Chronic Disease (Home Care) Research Center, School of Nursing \\ and Midwifery, Hamadan University of Medical Sciences, Hamadan, Iran \\ 2. Student Research Center, School of Nursing and Midwifery, Hamadan University of Medical Sciences, Hamadan, \\ Iran \\ 3. Associate Professor, Ph.D. in reproductive health, School of Nursing and Midwifery, Hamadan University of \\ Medical Sciences, Hamadan, Iran \\ 4. Associate Professor, Faculty of Health, Hamadan University of Medical Sciences, Hamadan, Iran
}

Article Info $\quad$ ABSTRACT

Received: 2019/05/18;

Accepted: 2019/06/06;

Published Online: 2019/08/28

10.30699/sjhnmf.27.6.424

Original Article

Use your device to scan and read the article online

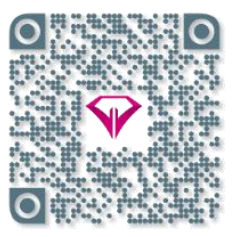

Introduction: Mothers of cesarean section need more support for breastfeeding. The purpose of this study was to use Bristol's tool for lactation counseling on the breastfeeding status in mothers undergone Cesarean section.

Methods: In this quasi-experimental study, 80 primiparous women after cesarean section In Fatemieh Hospital of Hamedan in year 2018 were selected by available sampling method and assigned to two groups of test (pairs) and control (individual days) (40 persons per group). In two groups, the researcher reviewed the Bristol Breastfeeding checklist, assessed the breastfeeding status, nuchal infant, milk swallowing and infant suction and, based on the need, a breastfeeding counselor was provided in the test group. The counseling was given to the mother during the first 2 hours, 2 days, 10 days and one month after delivery. During this time, the control group received routine care only. The lactation continuity questionnaire was completed for both groups during the four months after delivery.

Results: Two groups had no significant differences in demographic variables $(P$ $>0.05)$. There was a significant difference between the mean duration of lactation during the four months postpartum $(P<0.001)$. The mean of Bristol instrument scores in the first session did not have a significant difference between the two groups, but in the second, third and fourth sessions after delivery, there was a significant difference between the two groups $(P<0.001)$.

Conclusion: The Bristol tool is a good tool for evaluating mothers breastfeeding. Keywords: Breastfeeding, Exclusive breastfeeding, Consultation, Cesarean sections, Delivery

Corresponding Information:

Farzaneh Soltani, Associate Professor, Ph.D. in reproductive health,School of Nursing and Midwifery, Hamadan University of Medical Sciences, Hamadan, Iran. Email: farzanehsoltani2008@yahoo.com

Copyright $\odot$ 2020, This is an original open-access article distributed under the terms of the Creative Commons Attribution-noncommercial 4.0 International License which permits copy and redistribution of the material just in noncommercial usages with proper citation.

\section{How to Cite This Article:}

Parsa P, Khodabaneloo R, Soltani F, Mohamadi Y. The Use of Bristol's tool in lactation Counseling and its Impact on the Breastfeeding Status in Primiparous Mothers Undergone Cesarean Section. Avicenna J Nurs Midwifery care. 2019; 27 (6) :424-431 
استفاده از ابزار بريستول (BBAT) در مشاورة شيردهى و تأثير آن بر وضعيت شيردهى مادران سزارينى نخستزاى

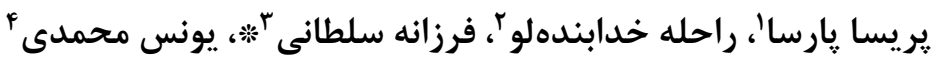

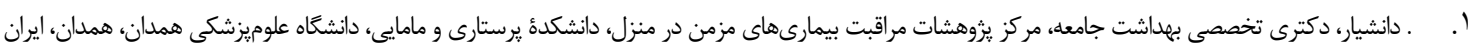

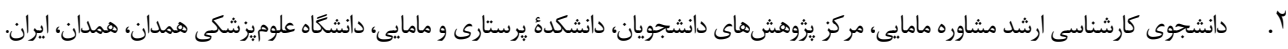

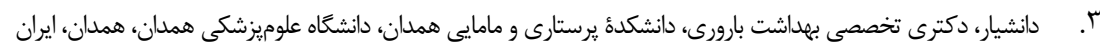

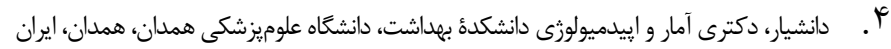

\begin{tabular}{|c|c|}
\hline קֶيده & اطلاعات مقاله \\
\hline 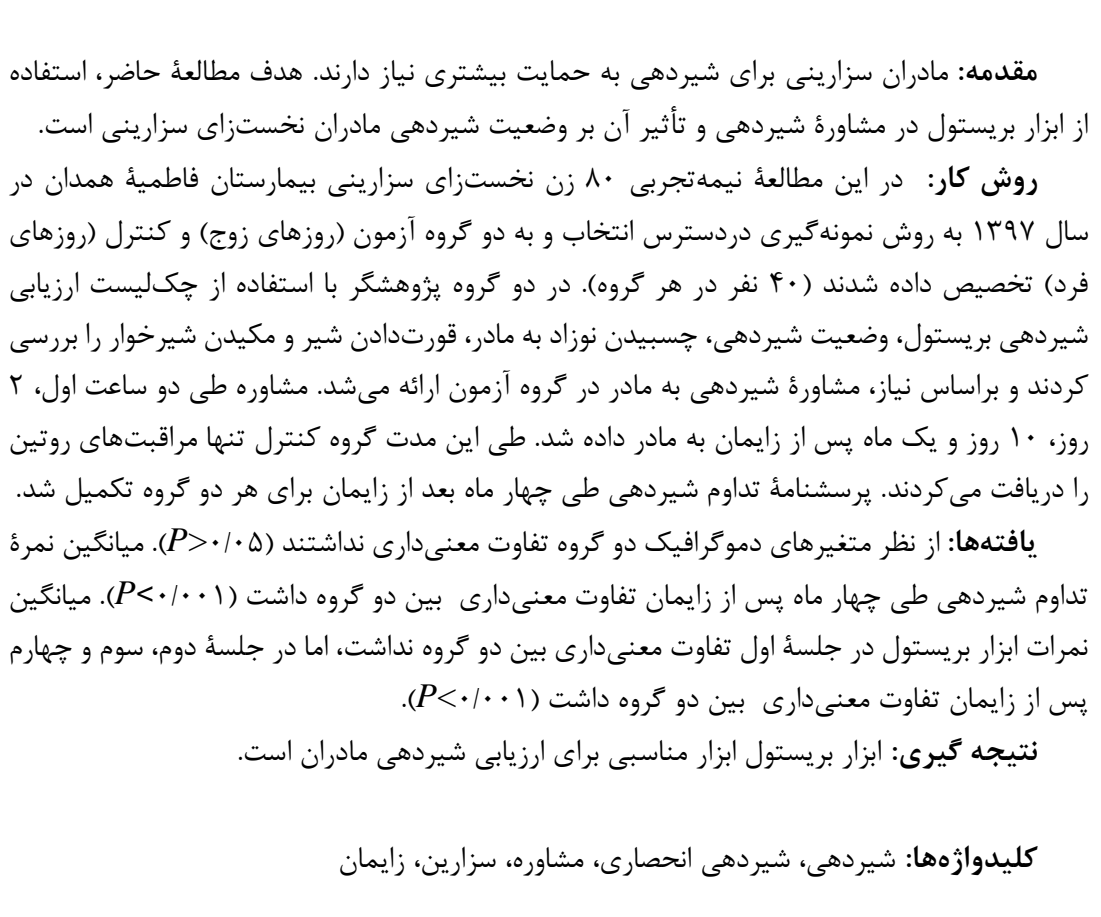 & 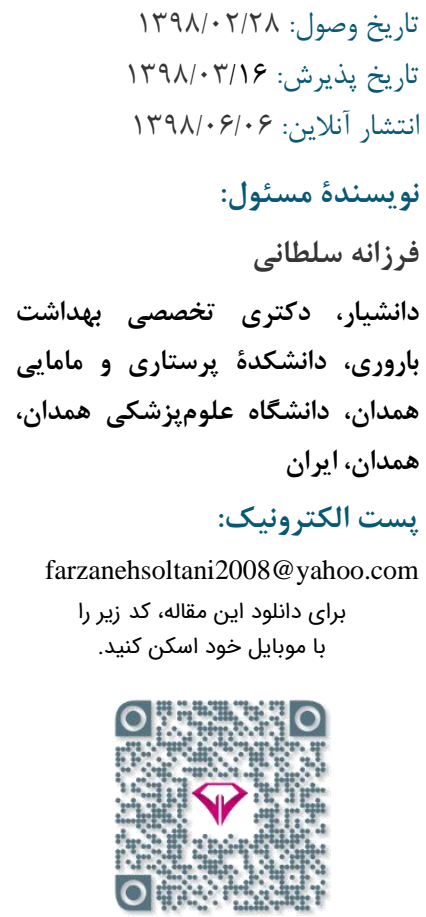 \\
\hline
\end{tabular}

مقدمه

شيردهى انحصارى در زنان آمريكايى در ابتداى دورهٔ بعد

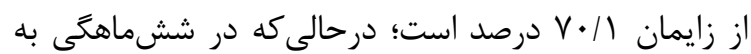

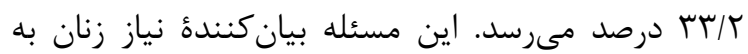

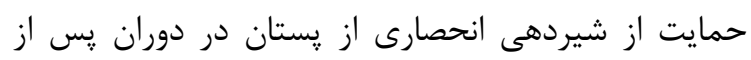

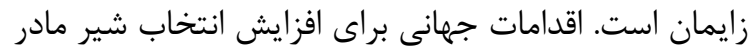
و طولانى كردن مدت شيردهى انحصارى مدنظر است، اما

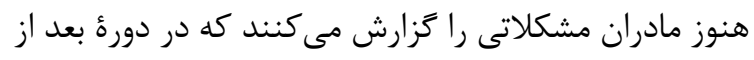

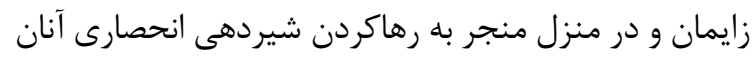

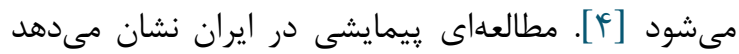

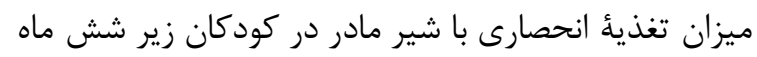

امروزه اهميت شيردهى انحصارى به نوزاد در كاهش

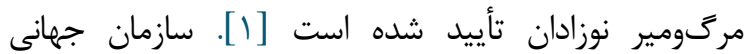
بهداشت، تغذئُ انحصارى با شير مادر را تا شش ماه اول زندگى

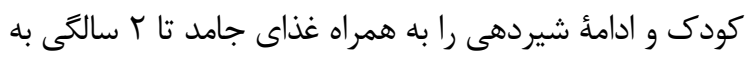
مادران توصيه كرده است كه در اين راستا، شش ماه اول پِ إن از تولد، مهمترين و بحرانىترين دوره براى رشد و تكامل شيرخوار

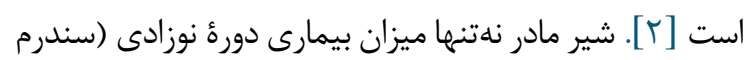

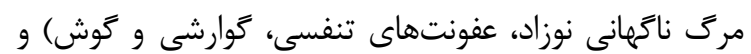
كودكى (آلرزى، آسم، جاقى) را كاهش مي عـدهد، بلكه ميزان سرطان تخمدان و سرطان سينه رادر مادر كمتر مى كند [ب]. 
بيمارستانهاى دوستدار كودى اضافه شد و ابزار ه آيتمى بريستول ساخته شد كه براساس آن به شيردهى مادر نمره

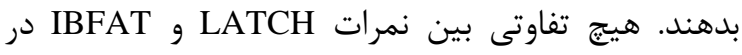

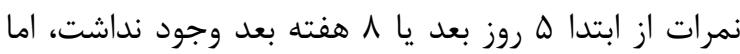
نمرات ابزار IBFAT در كروه آزمايش نسبت به كروه كنترل

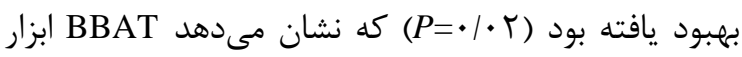

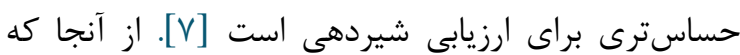
تاكنون از ابزار بريستول در ايران استفاده نشده است و باى إنائ

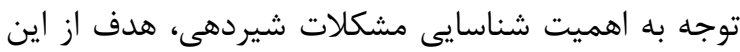
يزوهش استفاده از ابزار بريستول (BBAT) در مشاورة

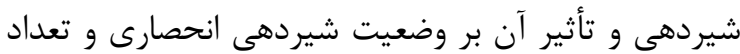

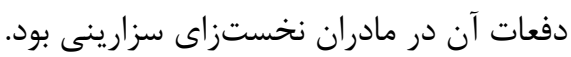

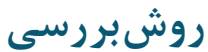

مطالعه حاضر نيمهتجربى و با طرح ييشآزمون و

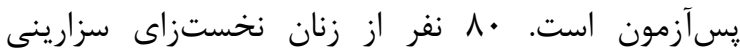

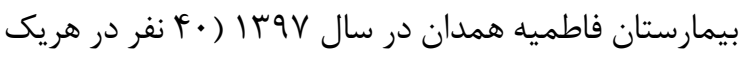
از دو گروه كنترل و آزمون) به روش دردسترس (روزهاى

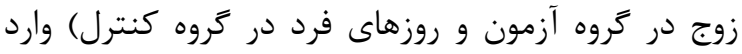
مطالعه شدند. معيارهاى ورود به مطالعه شامل زايمان به رونه

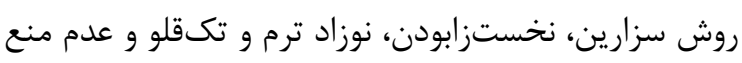

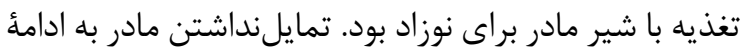
همكارى، حضورنداشتن مداوم خانم در حداقل در يك جلسهٔ نأن

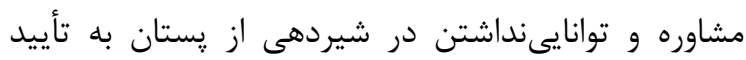

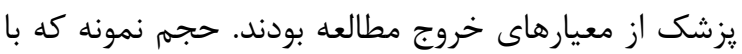

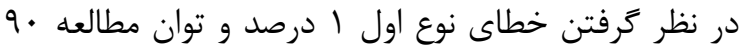

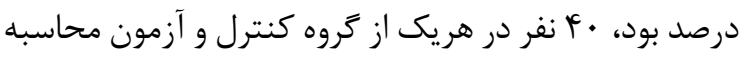

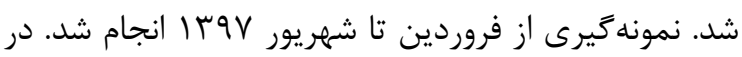
اولين ملاقات با مادر كه طى دو ساعت اول يس إز زئ زايمان

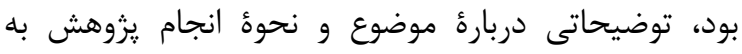

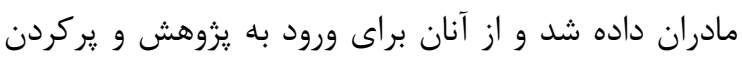
فرم برسشنامه، رضايتنامه آكاهانه دريافت شد. در دو دو كروه

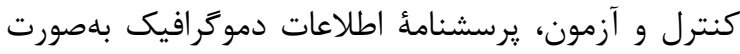

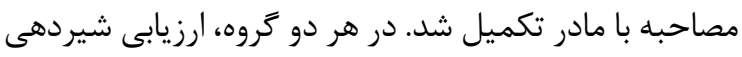

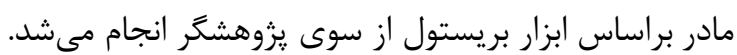

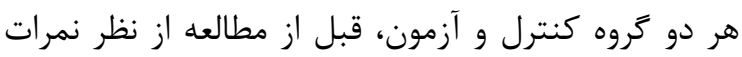

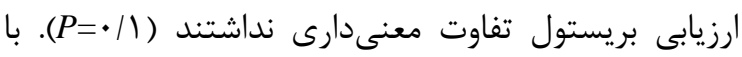

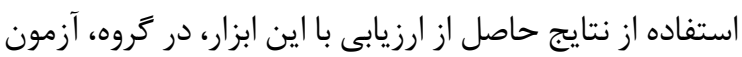

آس در درد است. در عين حال با تلاشهاى فراوان در كشور

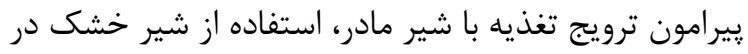

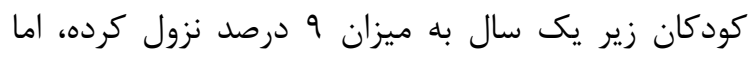

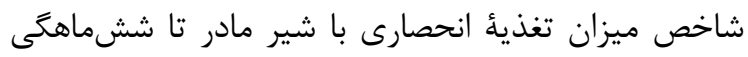

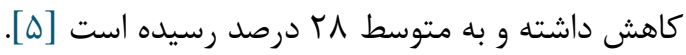

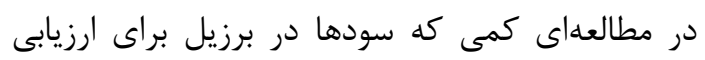
الكوى تغذئ نوزادان درباره تغذيه با شير مادر و و تعيين

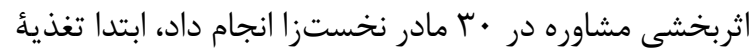

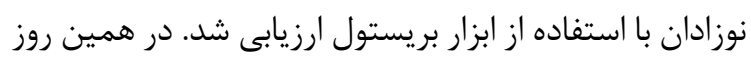

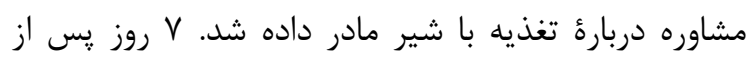
مشاوره، براى ارزيابى اثربخشى مشاوره از مادران يسآ آزمون

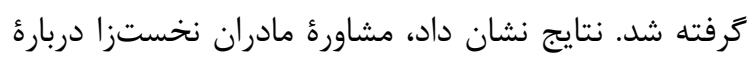
تكنيك تغذيه با شير مادر موجب بهببود شيردهيى آنان

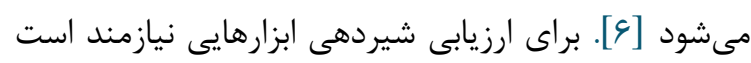
تا بتوان نحوه شيردهى را ارزيابى كرد و براساس آن آن مشاورة

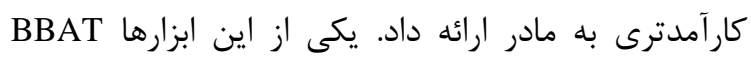
(Bristol Breastfeeding Assessment Tool) شامل ץ آيتم (وضعيت شيردهى، جسبيدن نوزاد به مادر،

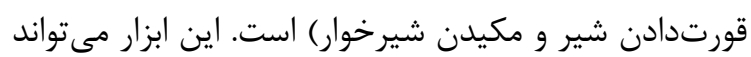

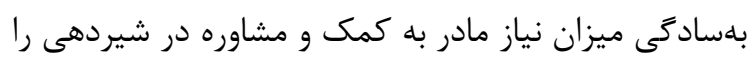

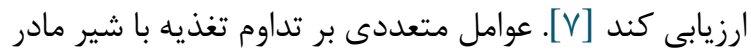

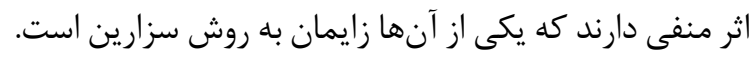

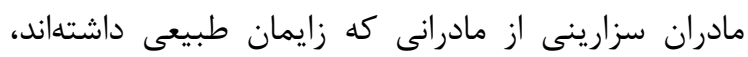
بهويزه در وضعيت صحيح شيردادن به شيرخوار خود به إنه كمك و حمايت بيشترى نياز دارند [N]. برنامههاى حمايت

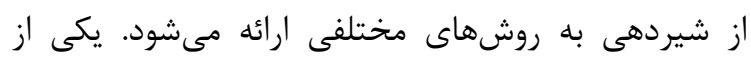

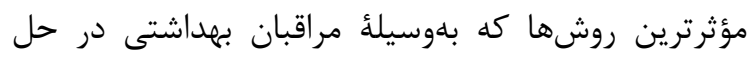
مشكل مددجو استفاده مىشود، مشاوره است [9]. در مطالعئ

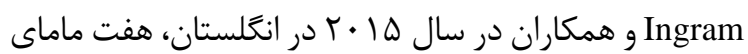
كارشناس شيردهى فاكتورهاى ارزيابى شيردهى ران را درباره

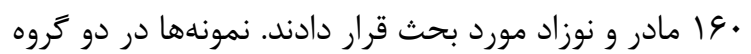

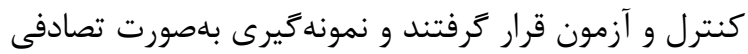

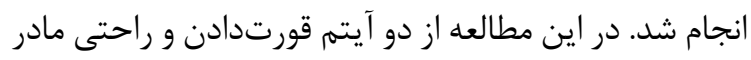
از ابزار Swallowing, Type ) (Latch, Audible) LATCH of Nipple, Comfort, Hold (Infant Breast Feeding Assessment Tools) IBFAT استفاده شد و دو آيتم جديد وضعيت شيردهى و جسبيدن مادر به نوزاد نيز براساس مطالعات مبتنى بر شواهد و قوانين 
شيردهى نمرة |، شيردهى كمتر از 1 بار نمرءٔ ז، شيردهى

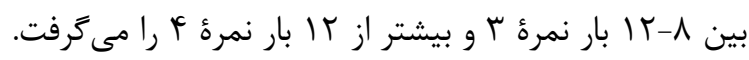

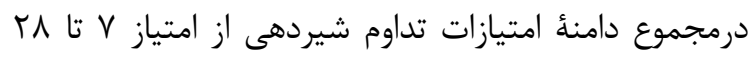

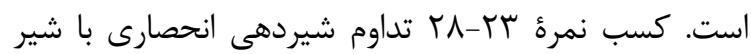
مادر در نظر كرفته مىشود. بهمنظور تعيين روايى ابزار از روش دئي

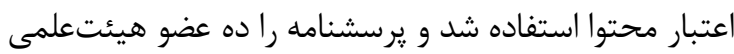

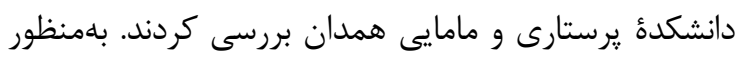

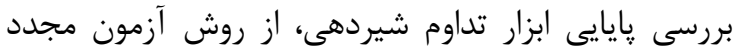

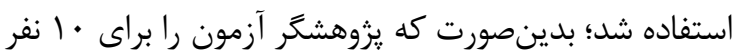

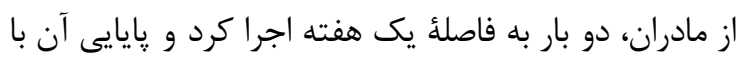
شاخص r = r به دست آمد. يس از كردآورى دادهها، تلخيص دادهها با استفاده از آمار

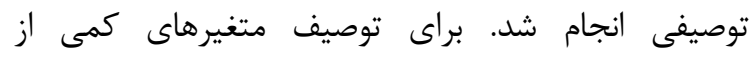
شاخصهاى مركزى و يراكندگى استفاده شد. براى مقايسٔ توصن

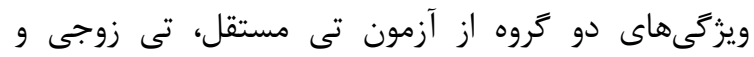

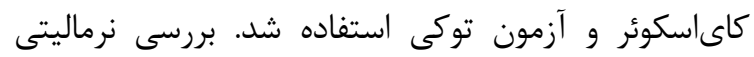

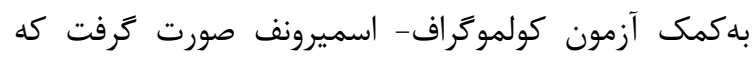

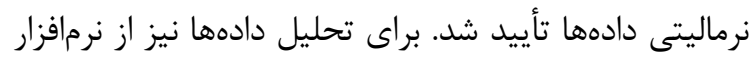

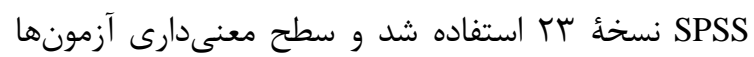
كمتر از له درصد در نظر كرفته شد.

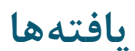

يافتههاى يزوهش براساس جدول ا نشان مىدهد، دو كروه از نظر متغيرهاى دموكرافيك (سن، شغل و تحصيلات مادران

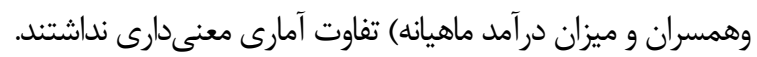

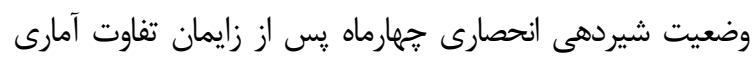

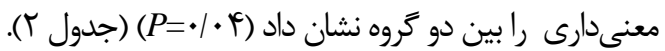

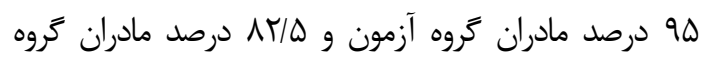

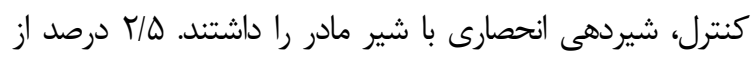

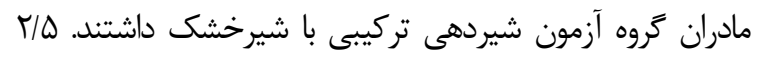

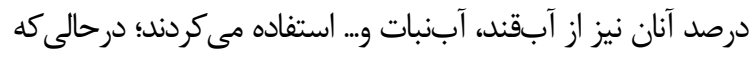

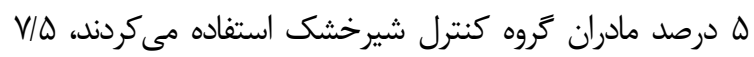

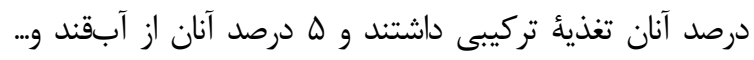

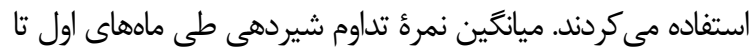

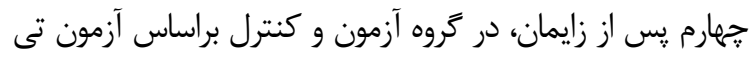

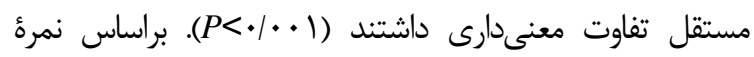

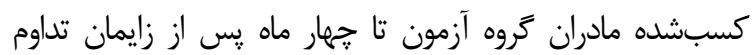

$$
\text { شيردهى با شير مادر داشتند (جدول ؟r). }
$$

مشاورهاى براى تغذيئ صحيح نوزاد، وضعيت مادر و نوزاد و

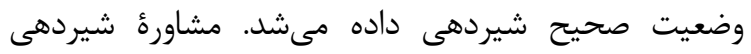

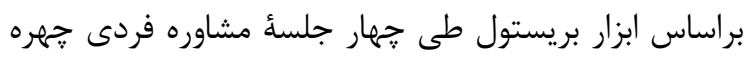

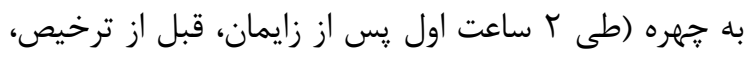

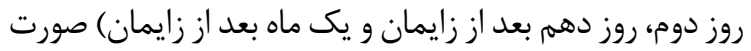

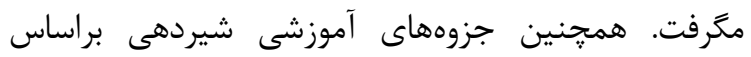

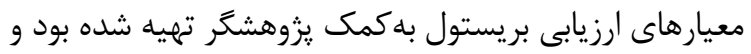

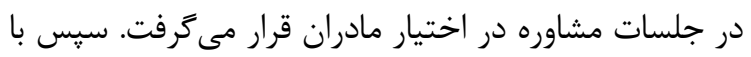

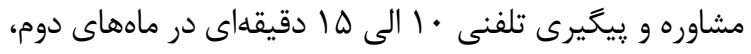

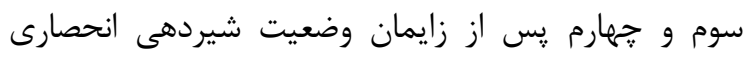

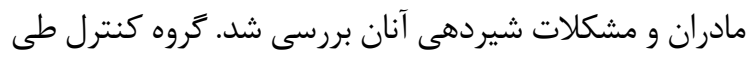

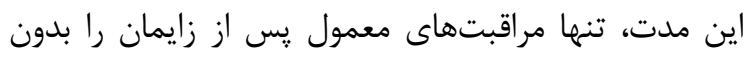
دخالت يزوهشكر دريافت مى كردند و ارزيابى بريستول مشابه مدابه

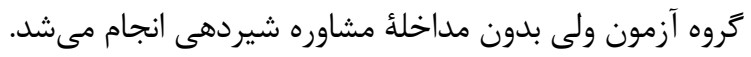

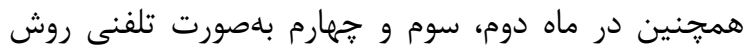

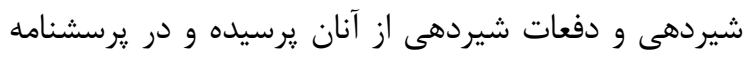

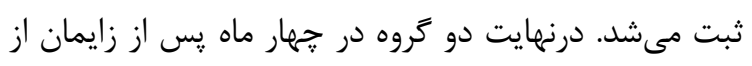
نظر نمرات بريستول، وضعيت شيردهى انحصارى و تعداد دفعات شيردهى با يكديخر مقايسه شدند.

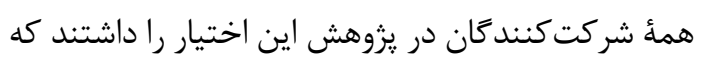
در هر مرحلهاى از يزوهش در صورتى كه تمايل به ادامه همكارى نداشتند از مطالعه خارج شوند. ابزار جمع آورى دادهها

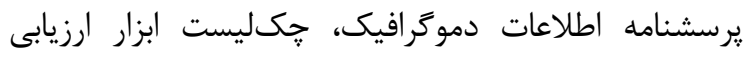
شيردهى بريستول، يرسشنامه وضعيت شيردهى انحصارى و و

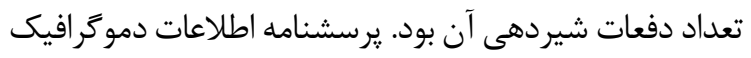

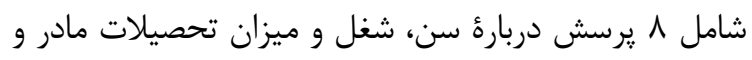

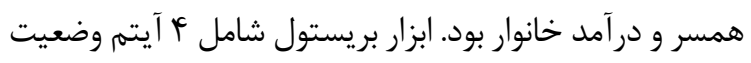
شيردهى، جسبيدن به مادر، مكيدن و قورتدادن است كه به به

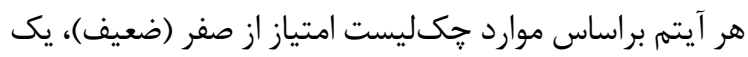

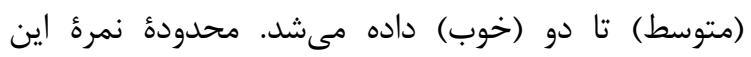

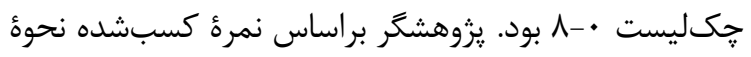

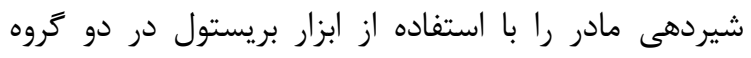

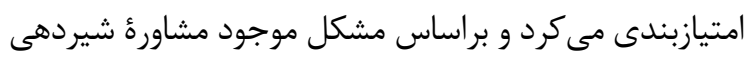

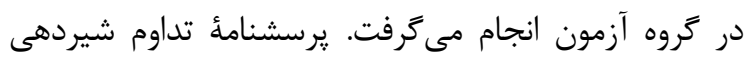

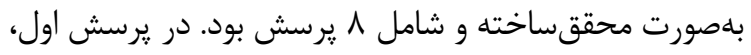

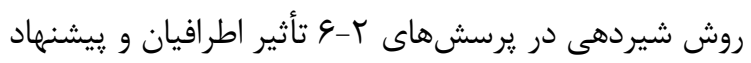

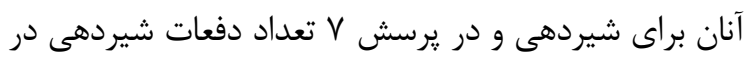

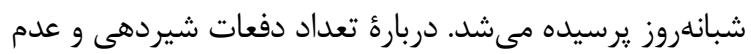


جدول ا. توزيع فراوانى و مقايسه مادران دو كروه آزمون و كنترل برحسب متغيرهاى دموكرافيك

\begin{tabular}{|c|c|c|c|c|c|c|c|}
\hline \multirow[t]{2}{*}{ P value } & \multirow[t]{2}{*}{ آماره } & \multirow{2}{*}{$\begin{array}{c}\text { كنترل } \\
\text { (درصد) تعداد } \\
\text { N=r. }\end{array}$} & \multirow{2}{*}{$\begin{array}{c}\text { آزمون (درصد) تعداد } \\
\text { N=f. }\end{array}$} & \multicolumn{2}{|c|}{ (انحراف معيار) } & \multirow[t]{2}{*}{ سطوح متغير } & \multirow[t]{2}{*}{ متغير } \\
\hline & & & & كنترل & آزمون & & \\
\hline - IfF & $* \cdot / 91$ & & & $\begin{array}{l}r F / 90 \\
(9 / 9 \Lambda)\end{array}$ & $\begin{array}{l}|q /\rangle . \\
(g / Y Q \Delta)\end{array}$ & سن مادر & \multirow[b]{2}{*}{ سن س } \\
\hline$\cdot / r V$ & $* \cdot / \Lambda$. & & & $\begin{array}{l}r \cdot / r \Delta \\
(s / 1 V)\end{array}$ & $\begin{array}{l}r \mid / \mathcal{F} \\
(D / F F)\end{array}$ & سن يدر & \\
\hline \multirow{2}{*}{$\cdot / \Lambda$. } & \multirow{2}{*}{$* * 1 / r \Delta$} & $r(V / \Delta)$ & $f(1 \cdot)$ & & & شاغل & \multirow{2}{*}{ شغل مادر } \\
\hline & & $r V(q Y / \Delta)$ & एq (१•) & & & خانهدار & \\
\hline \multirow{4}{*}{.190} & \multirow{4}{*}{ *** } & $r(V / \Delta)$ & $f(1 \cdot)$ & & & كارمند & \multirow{4}{*}{ شغل پيدر } \\
\hline & & $\|(r \cdot)$ & $9(Y Y / Q)$ & & & كارگر & \\
\hline & & $r \Delta(\Phi T / D)$ & $T V(\Phi V / D)$ & & & آزاد & \\
\hline & & - & - & & & بيكار & \\
\hline \multirow{3}{*}{$\cdot / \pi \Delta$} & \multirow{3}{*}{$* * T / r \Lambda$} & $19(4 \cdot)$ & $\|(T r / D)$ & & & ابتدايى & \multirow{3}{*}{ تحصيلات مادر } \\
\hline & & $r \cdot(\Delta \cdot)$ & $\backslash \wedge(F \Delta)$ & & & متوسطه & \\
\hline & & $f(1 \cdot)$ & $9(Y Y / Q)$ & & & دانشكاهى & \\
\hline \multirow{3}{*}{$\cdot|r|$} & \multirow{3}{*}{$* * \% / \cdot \Lambda$} & $r \cdot(\Delta \cdot)$ & $\operatorname{lf}(r \Delta)$ & & & ابتدايى & \multirow{3}{*}{ تحصيلات پدر } \\
\hline & & $1 \Delta(T V / \Delta)$ & $Y I(\Delta T / \Delta)$ & & & متوسطه & \\
\hline & & $\Delta(I Y / Q)$ & $\Delta(I T / \Delta)$ & & & دانشَاهى & \\
\hline \multirow{3}{*}{$\cdot / \Delta \Lambda$} & \multirow{3}{*}{$* * * / / r Y$} & $r(V / \Delta)$ & $r(\Delta)$ & & & . • . > هزار تومان & \multirow{3}{*}{ در آمد خانوار } \\
\hline & & $I V(F Y / D)$ & IT(Tr/Q) & & & $\begin{array}{c}\text { هزار تومان } \\
\text { ه }\end{array}$ & \\
\hline & & $r \cdot(\Delta \cdot)$ & $r \Delta(\Phi Y / \Delta)$ & & & >> ميليون تومان & \\
\hline
\end{tabular}

\section{*Independent t-test}

*** Chi-square test

جدول r. مقايسة وضعيت شيردهى مادران طى جهار ماه يس از زايمان در دو گروه كنترل و آزمون

\begin{tabular}{|c|c|c|c|c|c|}
\hline \multirow{3}{*}{$P$ value } & \multirow{3}{*}{ آمارة كاى دو } & K & \multicolumn{2}{|c|}{ تروه } & \multirow{3}{*}{ روش شيردهى } \\
\hline & & 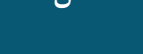 & كنترل & آزمون & \\
\hline & & (درصد) تعداد & (درصد) تعداد & (درصد) تعداد & \\
\hline \multirow{5}{*}{$\cdot 1 \cdot r$} & \multirow{5}{*}{$\mathrm{V} / \mathrm{I}$} & $\vee(\Lambda N / \vee \Delta)$ & س & ऍ (१८) & شيردهى انحصارى \\
\hline & & $r(T / \Delta)$ & $r(\Delta)$ & $(\cdot) \cdot$ & شير خشك \\
\hline & & $f(\Delta)$ & $r(V / \Delta)$ & $1(T / \Delta)$ & شير مادر و شيرخشك \\
\hline & & $r(\Gamma / V \Delta)$ & $r(\Delta)$ & $1(\Gamma / \Delta)$ & آبقند و... \\
\hline & & $\wedge \cdot(1 \cdots)$ & $f \cdot(1 \cdots)$ & $f \cdot(1 \cdots)$ & 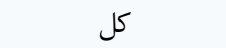 \\
\hline
\end{tabular}




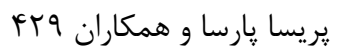

جدول r. مقايسُٔ ميانكَين نمرةٌ تداوم شيردهى مادران طى جهار ماه يِ از زايمان در دو تروه كنترل و آزمون

\begin{tabular}{|c|c|c|c|c|}
\hline \multirow{2}{*}{$P$ value } & \multirow{2}{*}{ 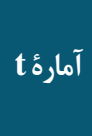 } & \multicolumn{2}{|c|}{ 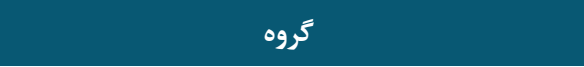 } & \multirow{3}{*}{ 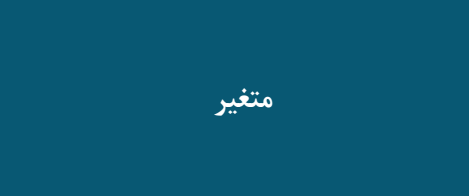 } \\
\hline & & 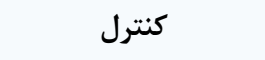 & 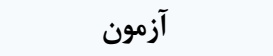 & \\
\hline & & (انحراف معيار) ميانغين & (انحراف معيار) ميانتين & \\
\hline$<\cdot / \cdot \cdot 1$ & g/VA & TGIGT $(T / 1)$ & TS/TD $(1 / \mathcal{T})$ & نمرةٌ تداوم شيردهى يك ماه پِ از زايمان \\
\hline$<\cdot / \cdot \cdot 1$ & SINV & $T r / \Delta D(T / 9)$ & $r g / \mid V(1 / Q)$ & نمرة تداوم شيردهى دو ماه پِس از زايمان \\
\hline$<\cdot / . \cdot 1$ & D/TS & $T Y / I T(T / V)$ & $\operatorname{TaV}(T / \Gamma)$ & نمرةٔ تداوم شيردهى سه ماه يِ از زايمان \\
\hline$<\cdot \mid \cdot \cdot 1$ & SITA & $r J / A V(T / T)$ & $r \omega / \Lambda V(\Psi / \Gamma)$ & نمرةٔ تداوم شيردهى جهار ماه پِ از زايمان \\
\hline
\end{tabular}

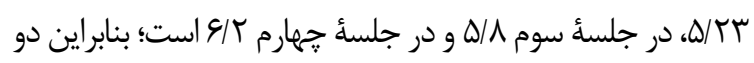

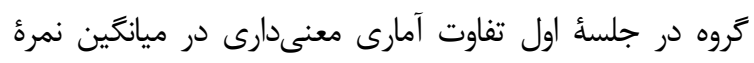

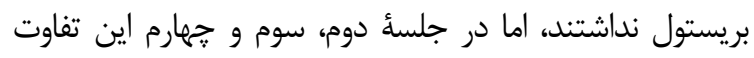

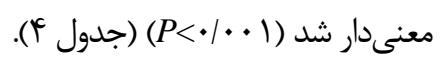

براساس نتايج بهدستآمده در جدول أل، ميانكين نمره جهار

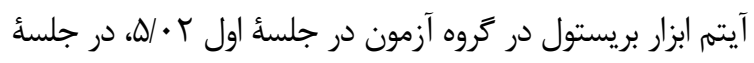

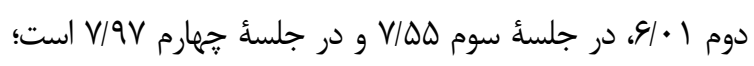

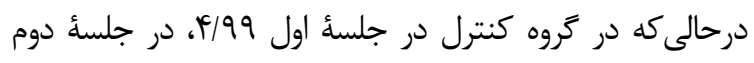

جدول Fا. مقايسهُ ميانگين نمرءٔ كل ابزار بريستول در جهار جلسهُ مشاوره در دو كروه

\begin{tabular}{|c|c|c|c|c|}
\hline P value & to آمارة t & 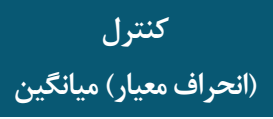 & 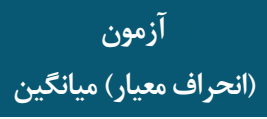 & جلسة مشاوره \\
\hline$P=\cdot / 1$ & $1 / V \Delta$ & $4 / 99(1 / 94)$ & $Q / \cdot T(I / G T)$ & r ساعت اول يس از زايمان \\
\hline$P<\cdot \mid \cdot \cdot 1$ & $\Delta / r$ & D/TY (I/GT) & $91 \cdot 1(1 / \cdot V)$ & روز دوم قبل از ترخيص \\
\hline$P<\cdot / \cdot \cdot 1$ & $r / V$ & $\Delta / \wedge(1 / \& Y)$ & $V / \Delta Q(\cdot / \mathcal{K} T)$ & • • ا روز پس از زايمان \\
\hline$P<\cdot / \cdot \cdot 1$ & $k / \varepsilon$ & $9 / \cdot r(1 / 9 T)$ & $V / q V(\cdot / \Delta r)$ & يك ماه يس از زايمان \\
\hline
\end{tabular}

[IT] [I در اين بزوهش، مقايسٔ وضعيت شيردهى انحصارى با

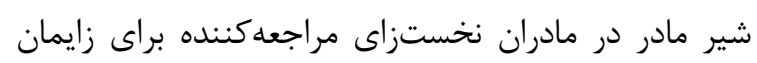

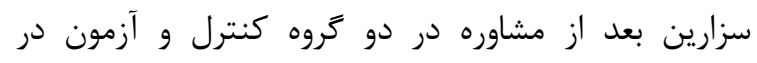

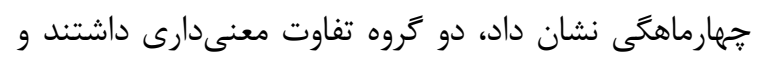

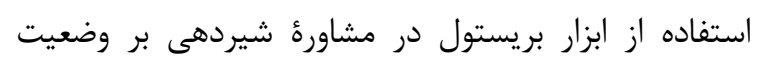

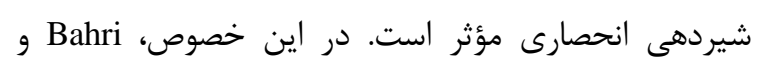

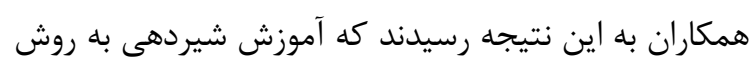

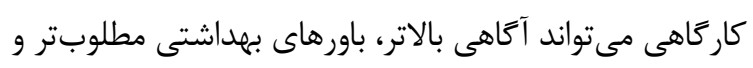

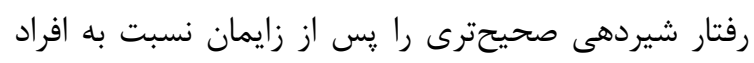

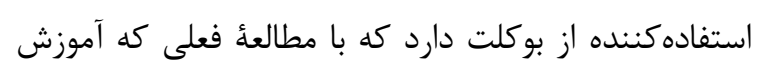

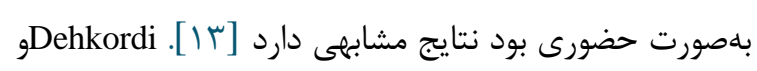

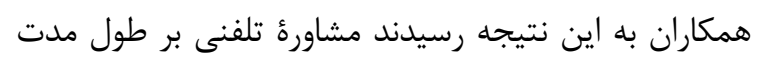

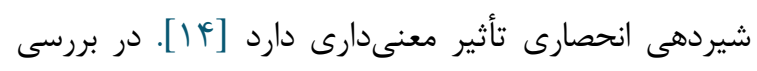

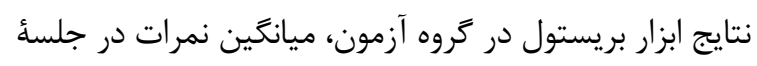

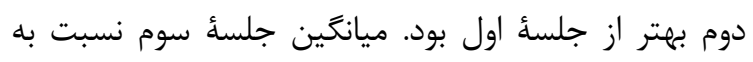
جلسةٔ اول و دوم بيشتر بود و افزايش جشمخيرى داشت، اما هدف اين مطالعه استفاده از ابزار بريستول (BBAT) در

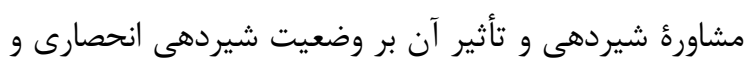

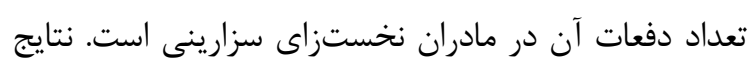

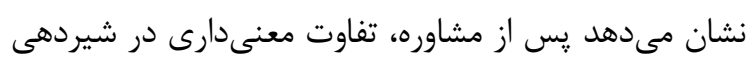

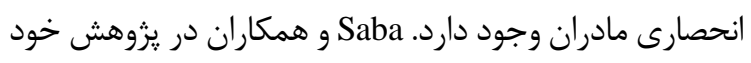

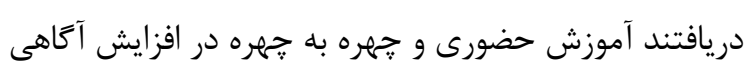

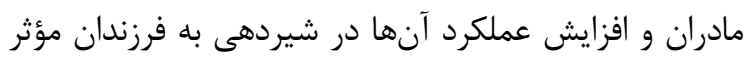

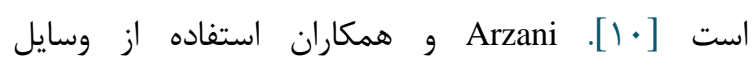

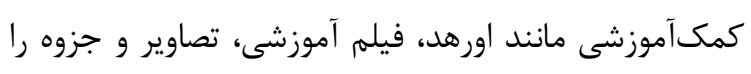

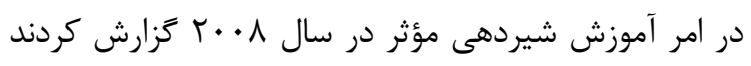

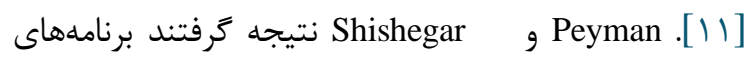

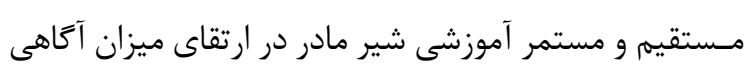

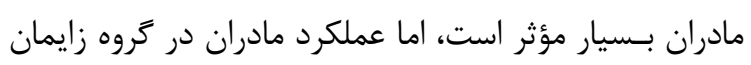

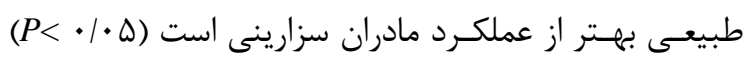




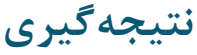

مادران سزارينى براى شيردهى به حمايت بيشترى نياز

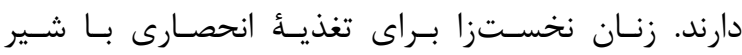

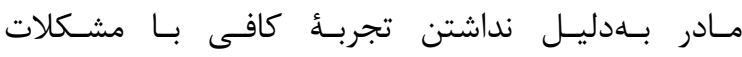
بيشـترى مواجـه خواهنــد بـود. از آنجا كه ماماها از اولين افرادى هستند كه يس از زايمان در ارتباط با مادر قرار

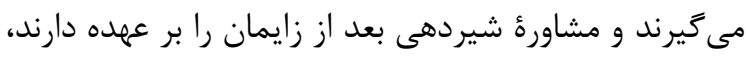

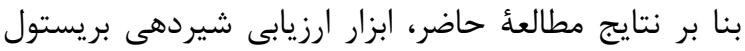

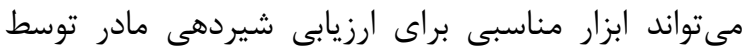

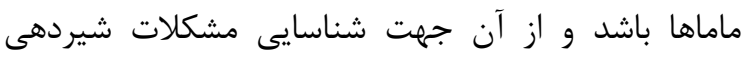
مادران و انجام مشاوره شيردهى مناسب استفاده كرد.

$$
\text { سياسگزارى }
$$

كد كار آزمايى بالينى اين يزوهش

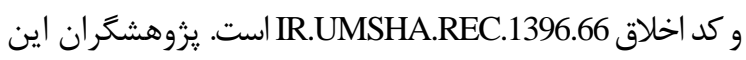
طرح مراتب تقدير و تشكر خود را از همكارى صميمانه

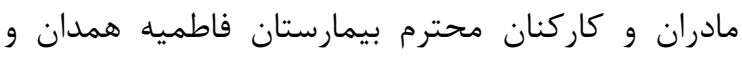

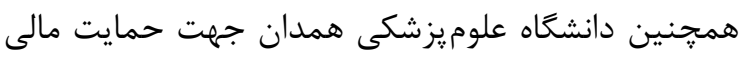
اين يزوهش اعلام مى كنند.

$$
\text { تعارض در منافع }
$$

بين نويسند

$$
\text { منابع مالى }
$$

منابع مالى اين مطالعه توسط نويسندًان تامين شده است.

\section{References}

1. World Health Organization. Infant and young child feeding: model chapter for textbooks for medical students and allied health professionals.

2. Veghari G, Mansourian A, Abdollahi A. Breastfeeding status and some related factors in northern Iran. Oman medical journal. 2011 Sep;26(5):342. [DOI:10.5001/omj.2011.84] [PMID] [PMCID]

3. Morowatisharifabad M, Hajizadeh $\mathrm{H}$, Akhavan Karbasi S, Fallahzadeh H. Study of the status of 6-12 months children exclusive breast-fed up to six months and its related factors in the urban health care centers of Ardakan city. Tolooebehdasht. 2013 Dec 10;12(3):84-94.
بين ميانگين نمرهٔ جلسأ جهارم و سوم تفاوت معنى دارى ديده نشد كه اين امر بيانگر وضعيت تثبيت شيردهى است.

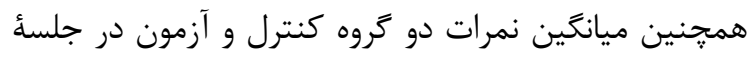
اول مشاوره تفاوت معنى دارى نداشت، اما در جلسةٔ دوم، سوم و جهارم اين تفاوت معنى دار بود كه اين مىتواند نشاندهنده

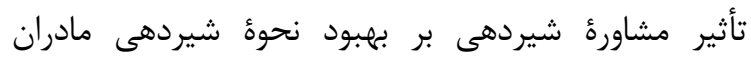
باشد. Ingram و همكاران نيز به اين نتيجه رسيدند. ميانخين بـاني

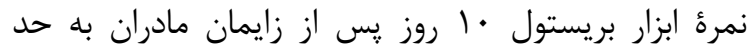

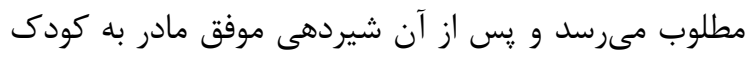

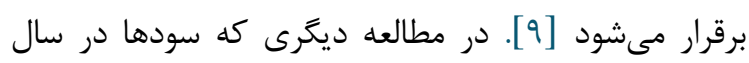

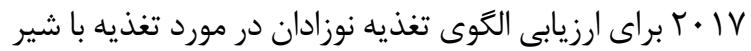

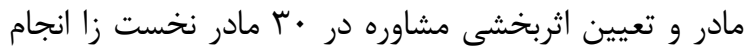

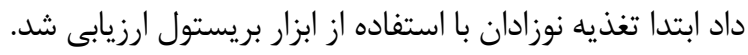

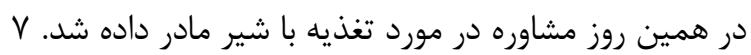
روز يس از مشاوره، براى ارزيابى اثربخشى مشاوره از مادران

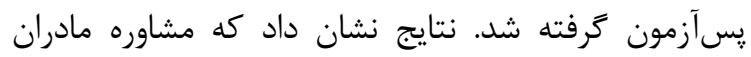
نخست زا در مورد تكنيك تغذيه با شير مادر موجب بهببود

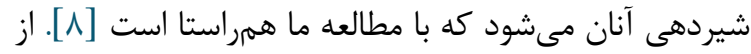
محدوديتهاى اين يزوهش مى توان به انجام اين مطالعه تنها در يك مركز درمانى اشاره كرد كه بهدليل محدوديت مراكز زايمان دولتى در شهر همدان است. از طرف ديگر تعداد دران محدود نمونه مىتواند از عموميت نتايج اين مطالعه بكاهد. از طرف ديخر، ييخيرى طولانىمدت بيشتر از أ ماه يس از زايمان

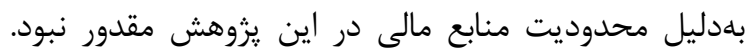
ريشنهاد مىشود يزوهشهاى بعدى با تعداد نمونهٔ بيشتر، مراكز زايمانى بيشتر و مدت بيخيرى طولانى تر انجام شوند.

4. O'Luanaigh P, Carlson C. Midwifery and Public Health E-Book: Future Directions and New Opportunities. Elsevier Health Sciences; 2005 Jun 15.

5. Olang B, Farivar K, Heidarzadeh A, Strandvik B, Yngve A. Breastfeeding in Iran: prevalence, duration and current recommendations. International breastfeeding journal. 2009 Dec;4(1):8. [DOI:10.1186/1746-4358-4-8] [PMID] [PMCID]

6. Sudha MB. A Study to Assess the Feeding Pattern of Infants Regarding Breast Feeding and To Determine the Effectiveness of Counselling Among Primi Para Mothers in Selected Hospitals at Puducherry. International Journal of Current Trends in Science and Technology. 2017;7(10):20171-5.

7. Ingram J, Johnson D, Copeland M, Churchill C, Taylor H. The development of a new breast feeding assessment tool and the relationship with breast 
يريسا پيارسا و همكاران اسץF

feeding self-efficacy. Midwifery. 2015 Jan 1;31(1):132-7. [DOI:10.1016/j.midw.2014.07.001] [PMID] [PMCID]

8. Sakkaki M, Khairkhah M. Promotion of exclusive breastfeeding: Teaching good positioning and support from fathers and families. The Journal of Urmia Nursing and Midwifery Faculty. 2013;10(6):824-31.

9. Badger T, Segrin C, Meek P, Lopez AM, Bonham E, Sieger A. Telephone interpersonal counseling with women with breast cancer: symptom management and quality of life. InOncology nursing forum 2005 Mar 1 (Vol. 32, No. 2). [DOI:10.1188/05.ONF.273-279] [PMID]

10. Saba MS, Bazmamoun H, Razavi Z. Comparison of face to face education with other methods to pregnant mothers in increase exclusive breast feeding. Avicenna Journal of Clinical Medicine. 2005 Dec 15;12(3):42-7.

11. Arzani AF, Kermanshahi S, Zahedpasha Y. The effect of educational intervention on continuous breast feeding in low birth weight infants. The Journal of Qazvin University of Medical Sciences. 2008 Aug 10;12(2):69-75.

12. Peyman A, Shishegar F. Comparison effect of breast feeding education on knowledge and function of cesarean and normal vaginal delivery mothers. J Urmia Nurs Midwifery Fac. 2007;5(4):53-63.

13. Bahri N, Bagheri S, Erfani M, Rahmani R, Tolidehi $\mathrm{H}$. The comparison of workshop-training and bookletoffering on knowledge, health beliefs and behavior of breastfeeding after delivery. The Iranian Journal of Obstetrics, Gynecology and Infertility. 2012;15(32):14-22.

14. Dehkordi ZR, Raei M, Shirazi MG, Dehkordi SA, Mirmohammadali M. Effect of telephone counseling on continuity and duration of breastfeeding among primiparus women. Hayat. 2012;18(2). 